\title{
Detection and Characterization by Mass Spectrometry of Radical Adducts Produced by Linoleic Acid Oxidation
}

\author{
Ana Reis, M. Rosário M. Domingues, Francisco M. L. Amado, \\ A.J.V. Ferrer-Correia, and Pedro Domingues \\ Department of Chemistry, University of Aveiro, Aveiro, Portugal
}

\begin{abstract}
The formation of linoleic acid radical species under the oxidative conditions of the Fenton reaction (using hydrogen peroxide and Fe (II)) was monitored by FAB-MS and ES-MS using the spin trap 5,5-dimethyl-1-pyrrolidine-N-oxide, DMPO. Both the FAB and ES mass spectra were very similar and showed the presence of ions corresponding to carbon- and oxygen centered spin adducts (DMPO/L; DMPO/LO; and DMPO/LOO). Cyclic structures, formed between the DMPO oxygen and the neighboring carbon of the fatty acid, were also observed. Electrospray tandem mass spectrometry of these ions was performed to confirm the proposed structure of these adducts. All MS/MS spectra showed an ion at $\mathrm{m} / \mathrm{z} 114$, correspondent to the $\left[\mathrm{DMPO}+\mathrm{H}^{+}\right.$, and a fragment ion due to loss of DMPO (loss of $113 \mathrm{Da}$ ), confirming that they are DMPO adducts. ES-MS/MS spectra of alkoxyl radical adducts (DMPO/LO) showed an additional ion at $\mathrm{m} / z 130[\mathrm{DMPO}-\mathrm{O}+\mathrm{H}]^{+}$, while ES MS/MS of peroxyl radical adducts (DMPO/LOO) showed a fragment ion at $m / z 146[\mathrm{DMPO}-\mathrm{OO}+\mathrm{H}]^{+}$, confirming both structures. Other fragment ions were observed, such as alkyl acylium radical ions, formed by cleavage of the alkyl chain after loss of water and the DMPO molecule. The identification of fragment ions observed in the MS/MS spectra of the different DMPO adducts suggests the occurrence of structural isomers containing the DMPO moiety both at $C_{9}$ and $C_{13}$. The use of ES tandem mass spectrometry, associated with spin trapping experiments, has beee shown to be a valuable tool for the structural characterization of carbon and oxygen-centered spin adducts of lipid radicals. (J Am Soc Mass Spectrom 2003, 14, 1250-1261) (c) 2003 American Society for Mass Spectrometry
\end{abstract}

$\mathrm{P}$ olyunsaturated fatty acids, such as linoleic acid, are the main components found in cell membranes of biological tissues. During cell metabolism, aerobic processes taking place at the mitochondria promote the formation of oxygen radicals known as reactive oxygen species (ROS). These ROS are cytotoxic and are removed by antioxidant systems occurring in living systems [1]. The ROS species such as hydroxyl $(\mathrm{OH})$ radicals, because of the unpaired electron in the oxygen atom, are very unstable and react readily with conjugated double bonds found in cell constituents such as lipids, proteins, and DNA bases, modifying the structures and damaging the tissues [2]. Oxidative damage is thought to cause a decrease in fluidity and disruption of the cell membrane, and to affect mitochondrial functions [3]. This has been connected to several age related diseases such as the case of Alzheimer's disease, Parkinson's disease, multiple sclerosis, and cataracts [2].

The lipid peroxidation reaction involves a number of

Published online August 26, 2003

Address reprint requests to Dr. P. Domingues, Department of Chemistry, University of Aveiro, 3810-193 Aveiro, Portugal. E-mail: pedrom@dq.ua.pt intermediate steps in a chain reaction forming lipid radicals ( $\left.\mathrm{L}^{\circ}, \mathrm{LO}^{\circ}, \mathrm{LO}\right)^{\circ}$ ), which in turn trigger the propagation of peroxidation reaction [4]. The extent of lipid peroxidation is used to estimate the extent of biological tissue damage. In in vitro assays, oxidative conditions may be induced by the addition of hydrogen peroxide to lipids in the presence of $\mathrm{Fe}^{2+}$ ions. This reaction, known as the Fenton reaction, leads to the formation of hydroxyl radicals, which then react, by a hydrogen abstraction mechanism, with unsaturated compounds such as lipids, forming radicals [5]. The radical species formed are very unstable, but the addition of nitroso compounds radicals, known as "spin traps", react with the lipid radicals leading to the formation of much more stable radical adducts. The radical adducts are usually examined by ESR spectroscopy [6-12].

Electron spin-trapping experiments are the most widely used approach for the identification of carboncentered lipid radicals formed during lipid peroxidation (after trapping with POBN [9-13]), or for the identification of oxygen-centered lipid radicals (after trapping with DMPO [7, 8, 14]).

Studies have demonstrated the applicability of mass 
spectrometry to the identification of carbon-centered radical adducts derived from lipids using the spin trap POBN [9, 11-13]. Other applications of mass spectrometry to the detection of spin adducts include the identification of alkyl radicals, namely POBN radical adducts of pentadienyl, by electrospray ionization ES-MS [15], and the detection and characterisation of hydroxyl-DMPO radical adducts by FAB-MS [16] and ES-MS [17, 18]. ES-MS has shown to be a valuable tool for the detection and characterization of oxidation radical products, mainly due to its high sensitivity, accuracy, simple sample preparation and the structural information obtained.

Both carbon- and oxygen-centered radicals occur during lipid oxidation, according to ESR results obtained during the investigation of reaction of linoleic acid with cytochrome $[7,13]$, or with soybean lipoxygenase [11]. The identification by ES-MS and tandem mass spectrometry of oxygen-centered lipid radicals using the DMPO spin trap has, to our knowledge, not yet been reported. In this work we will present the results of a study of the adducts of DMPO with the linoleic acid radical species produced under Fenton reaction conditions. The formation of the stable DMPO radical adducts was monitored by FAB-MS, ES-MS, and ES-MS/MS using our previously developed methodology [16].

\section{Experimental}

\section{Chemicals}

Linoleic acid and DMPO were obtained from Sigma (St. Louis, MO) and used without further purification. Nitrobenzyl alcohol (NBA) matrix was purchased from Merck (Darmstadt, Germany). Iron (II) chloride $\left(\mathrm{FeCl}_{2}\right)$ and hydrogen peroxide $\left(\mathrm{H}_{2} \mathrm{O}_{2}\right)$ used for the peroxidation reactions were purchased from Merck.

\section{Oxidation of Linoleic Acid by Fenton Reaction}

Spin trapping experiments for subsequent analysis by FAB-MS were done in the following manner. Approximately $100 \mathrm{ng}$ of linoleic acid in a chloroform solution (1 $\mu \mathrm{L})$, approximately $6 \mu \mathrm{mol}$ of hydrogen peroxide and $0.6 \mu \mathrm{mol}$ of $\mathrm{FeCl}_{2}$ were left to react for different periods of time. Then, $5 \mu$ l of DMPO and one drop of NBA matrix were added and the sample was analyzed by FAB-MS. Spin trapping experiments for subsequent ES-MS and ES-MS/MS were performed by adding to $100 \mathrm{ng}$ of linoleic acid, $5 \mathrm{mmol} \mathrm{FeCl}_{2}$ solution and 50 mmol of hydrogen peroxide $\left(\mathrm{H}_{2} \mathrm{O}_{2}\right)$ in $0.5 \mathrm{ml}$ of ammonium bicarbonate buffer solution ( $\mathrm{pH}$ 7.4). This mixture was left to react for different periods of time with occasional sonication, after which $1 \mu \mathrm{L}(9 \mathrm{mmol})$ of DMPO was added. The lipid oxidation products and spin adducts were extracted using a modified Folch method with chloroform:methanol (2:1, vol/vol) [19].

\section{FAB Mass Spectrometry}

Positive ion FAB mass spectra were acquired with a VG AutoSpecQ (VG Analytical Manchester, UK). The instrument is of EBE geometry and is equipped with a cesium gun. The applied accelerating voltage was $8 \mathrm{kV}$ and the cesium ion beam intensity was $3 \mu \mathrm{A}$ at $20 \mathrm{kV}$. In MS experiments, the EBE resolution was set to approximately 1500 .

\section{ES Mass Spectrometry}

Positive ion ES mass spectra and tandem mass spectra were acquired in a Q-TOF 2 instrument (Micromass, Manchester, UK) using a MassLynx software system (version 3.5). The samples for electrospray analysis were prepared by diluting $1 \mu \mathrm{L}$ of the sample with 200 $\mu \mathrm{L}$ of chloroform:methanol solution (1:1, vol/vol) containing $0.5 \%(\mathrm{vol} / \mathrm{vol})$ of acetic acid. Samples were introduced into the mass spectrometer using a flow rate of $10 \mu \mathrm{L} / \mathrm{min}$, setting the needle voltage at $3000 \mathrm{~V}$ with the ion source at $80^{\circ} \mathrm{C}$ and cone voltage at $35 \mathrm{~V}$. Tandem mass spectra (MS/MS) of the protonated molecules were obtained by collision-induced dissociation (CID), using argon as the collision gas (Penning gauge pressure $\sim 6 \times 10^{-6} \mathrm{mBar}$ ) and varying collision energy between 20-35 eV. In MS and MS/MS experiments TOF resolution was set to approximately 9000 .

\section{Results and Discussion}

\section{Mass Spectrometry Analysis of DMPO Adducts}

The positive ion FAB mass spectrum of linoleic acid with $\mathrm{H}_{2} \mathrm{O}_{2}$ in the presence of $\mathrm{Fe}^{2+}$ and DMPO is shown in Figure 1a. For comparison, the mass spectrum of linoleic acid obtained under the same conditions but without the addition of $\mathrm{H}_{2} \mathrm{O}_{2}$ is shown in Figure $1 \mathrm{~b}$. Significant differences can be observed.

Comparing both spectra, new ions were observed in the presence of $\mathrm{H}_{2} \mathrm{O}_{2}$ and DMPO, namely the ions at $\mathrm{m} / \mathrm{z}$ 392-394, at $m / z 408-410$ and at $m / z 424-426$. These ions correspond to spin adducts of DMPO with radical species formed by the oxidation of linoleic acid under Fenton reaction conditions. They were not assigned as isolated oxidized species of the linoleic acid because they were not detected in the FAB mass spectrum of linoleic acid with $\mathrm{H}_{2} \mathrm{O}_{2}$ (spectra not shown). The ions of $\mathrm{m} / \mathrm{z}$ 394, 416, and 438 observed in Figure $1 \mathrm{~b}$ correspond to, respectively, the proton bound adduct of DMPO with the fatty acid, the sodium bound adduct of DMPO with the fatty acid and the sodium bound adducts of DMPO with the sodiated fatty acid.

The most abundant ions corresponding to DMPO adducts of linoleic acid radical species observed in Figure 1, are the ions at $m / z$ 392, 393, and 394, which were attributed to the carbon-centered radical adducts represented in Scheme 1a, b, c, respectively. Although DMPO is usually considered a spin trap more specific 


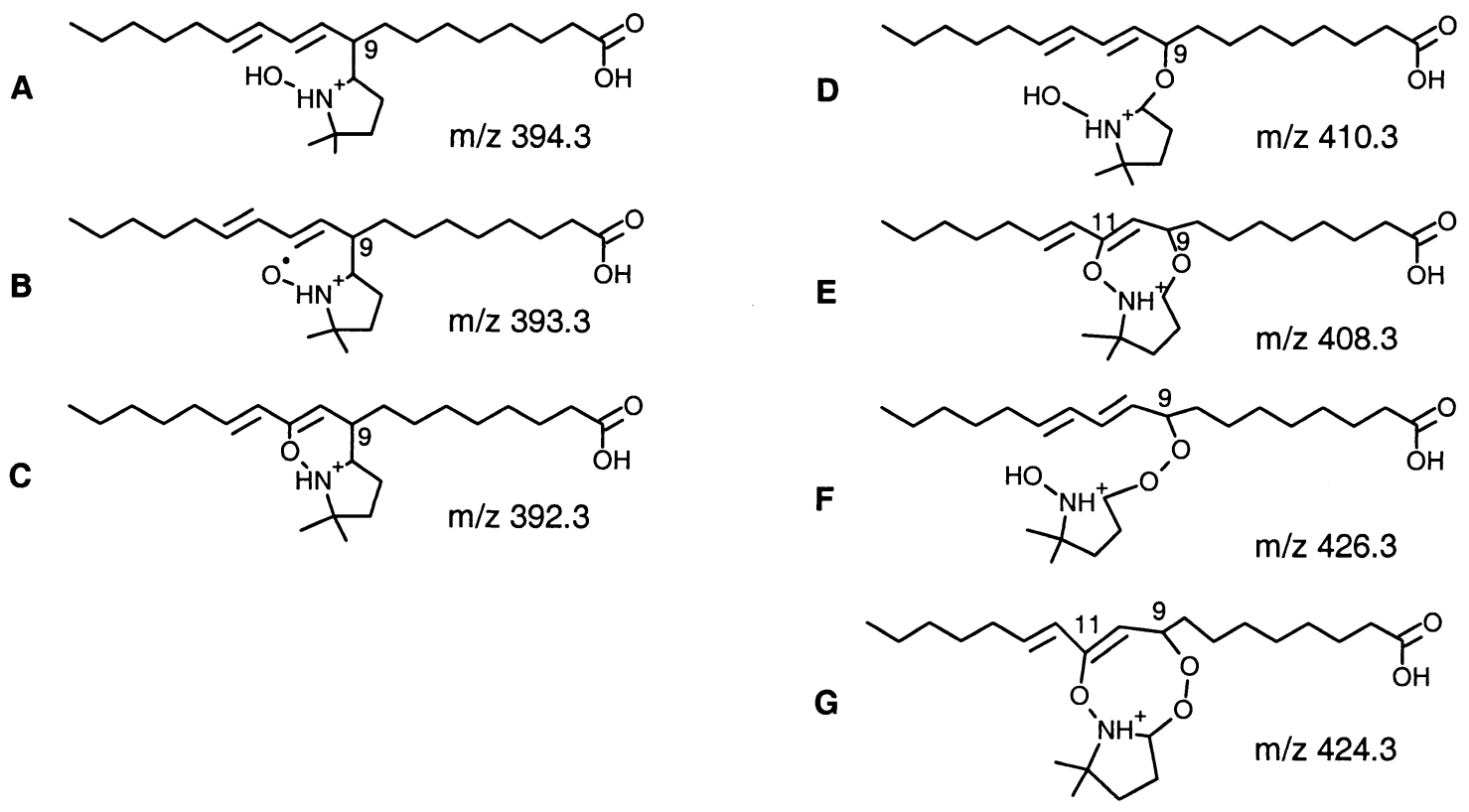

Scheme 1. Schematic structures of the DMPO spin radical adducts of the linoleic acid. The number on structures shows the carbon number.

for oxygen radicals, DMPO carbon-centered radicals have previously been observed during tryptophan oxidation [18].
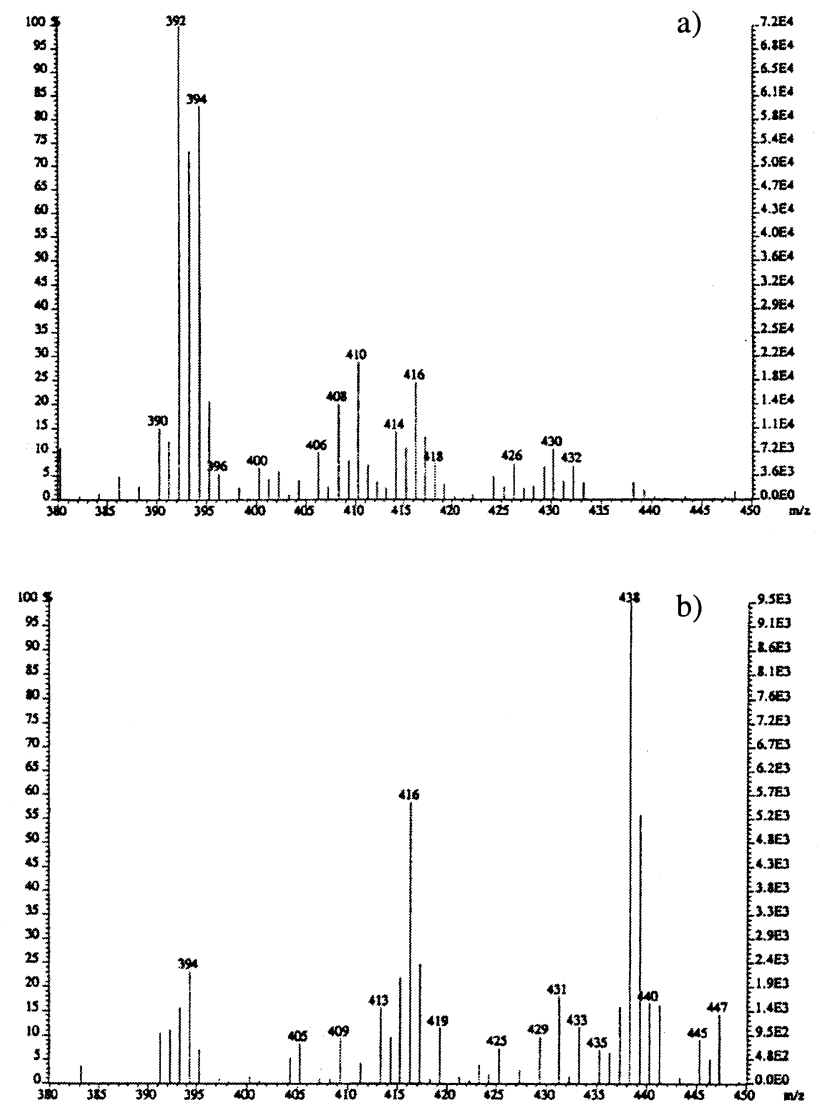

Figure 1. FAB-MS spectra of linoleic acid in presence of DMPO, (a) under oxidative conditions induced by Fenton reaction, and (b) under non-oxidative conditions.-
Additional ions at $m / z 408-410,16 \mathrm{Da}$ above the ions at $\mathrm{m} / \mathrm{z}$ 392-394, were attributed to alkoxyl (or hydroxyalkyl) radical adducts (DMPO/LO). The proposed structures for the ions at $\mathrm{m} / \mathrm{z} 410$ and 408 are presented in Scheme 1d, e. On another group of ions at $\mathrm{m} / \mathrm{z}$ 424-426, a further $16 \mathrm{Da}$ increase were assigned as peroxyl alkyl radical adducts (DMPO/LOO) of linoleic acid (Scheme 1g and $\mathbf{f}$ ). The structures proposed for these spin adducts presume the formation of an oxygen-centered radical, with the DMPO linked to the peroxyl alkyl radical. All the structures shown in Scheme 1 consider the radical adduct to be at the position $\mathrm{C}_{9}$, but it can also be placed at $\mathrm{C}_{13}$ [20].

The ions in each envelope correspond to different species of adducts, and have some structural differences. The ions at $\mathrm{m} / \mathrm{z} 392,408$, and 424 were attributed to cyclic radical adducts (Scheme $\mathbf{1 b}, \mathbf{e}, \mathbf{g}$ ). The other adducts (at $m / z$ 393, 409, and 425) are considered as open structure adducts although some are odd ions with an unpaired electron at the DMPO oxygen atom, as is represented in Scheme $\mathbf{1}$ for the adduct at $\mathrm{m} / \mathrm{z} 393$. The other adducts (at $m / z$ 394, 410 and 426) are evenelectron species (Scheme 1a, d, f). The unpaired electron will not be stable in solution and thus unlikely to occur significantly, which might explain the low relative abundance of these odd $\mathrm{m} / \mathrm{z}$ ions, when compared to the adjacent ions. Therefore, these odd mass ions will not be discussed further in this paper. The mass spectrum obtained after reaction with $\mathrm{H}_{2} \mathrm{O}_{2}$ (Figure 1a) also showed the presence of each of these clusters with an increase of $22 \mathrm{Da}$, which were attributed to the sodiated molecules of the DMPO adducts.

It is known that in the presence of reactive oxygen species (ROS) such as the hydroxyl radical formed by 


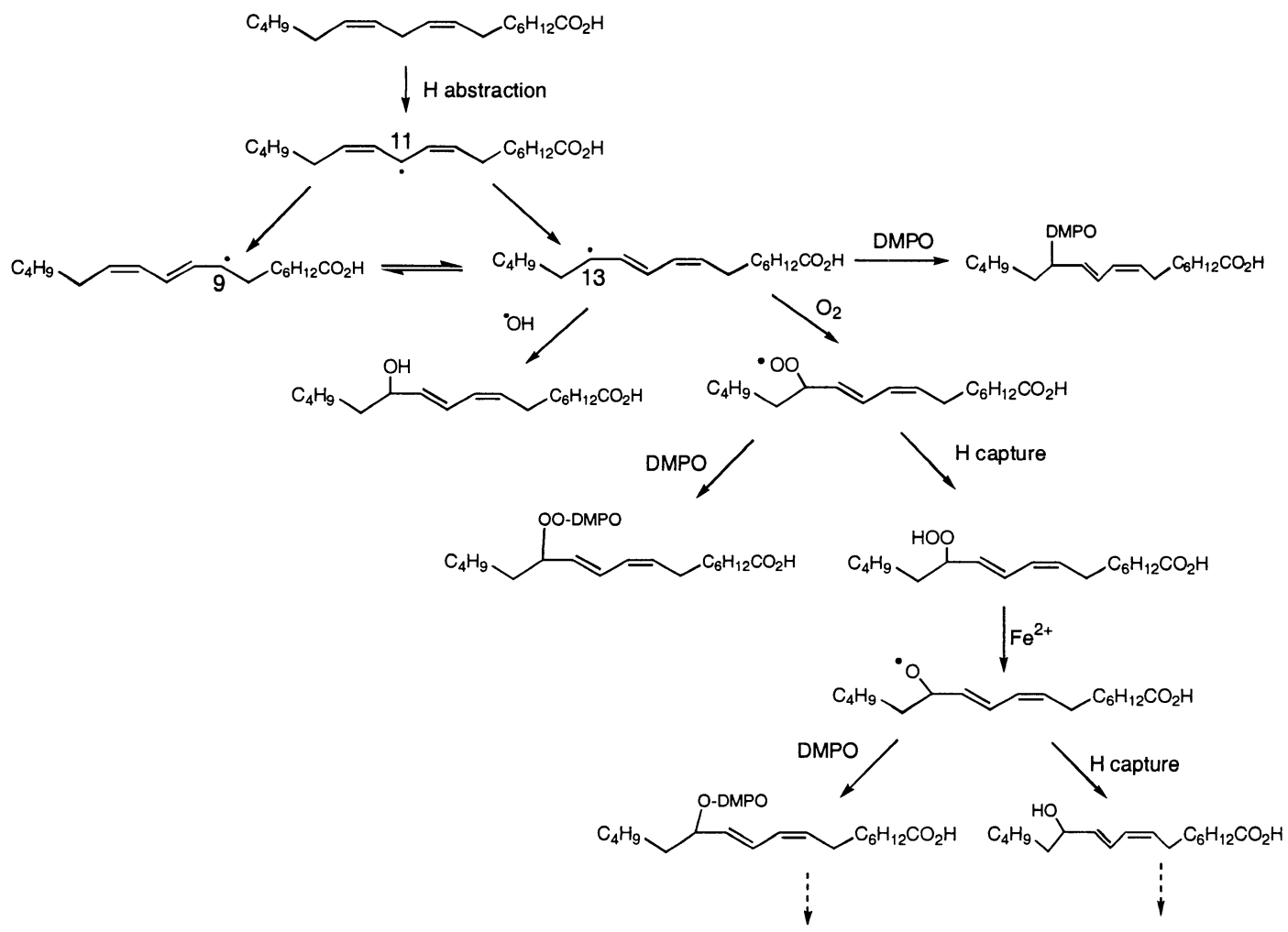

Scheme 2. Schematic representation of the pathways for the formation of the carbon and oxygencentered DMPO adducts of linoleic acid oxidation (adapted from references [11] and [14]).

the Fenton reaction, linoleic acid undergoes the removal of the bis-allylic hydrogen at carbon 11, leaving an unpaired electron and generating a carbon-centered radical (Scheme 2). This radical may be shifted, generating two stable resonant structures, with the radical either on $C_{9}$ or $C_{13}$ [20]. The radical can also be located in other places due to double bond migration, although their contribution should be minimal. Both carbon radical species (Scheme 2) may capture the spin trap, forming the carbon-centered adducts at $m / z$ 392-394 or they can take up an oxygen molecule, thus forming an alkyl peroxyl radical. The alkyl peroxyl radical may react with DMPO forming adducts at $m / z 424-426$, or may capture a hydrogen by abstraction from another
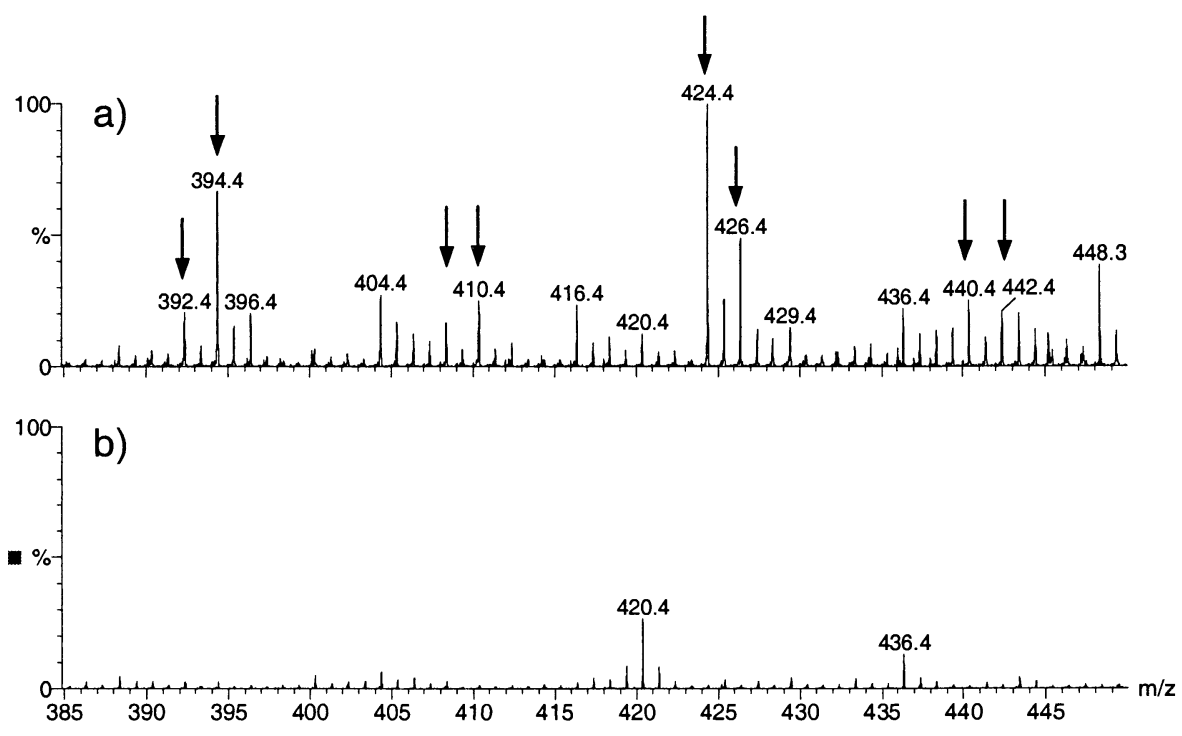

Figure 2. ES-MS mass spectra of linoleic acid in presence of DMPO (a) under oxidative conditions induced by Fenton reaction, and (b) under non-oxidative conditions. Arrows indicate new ions formed under oxidative conditions. 

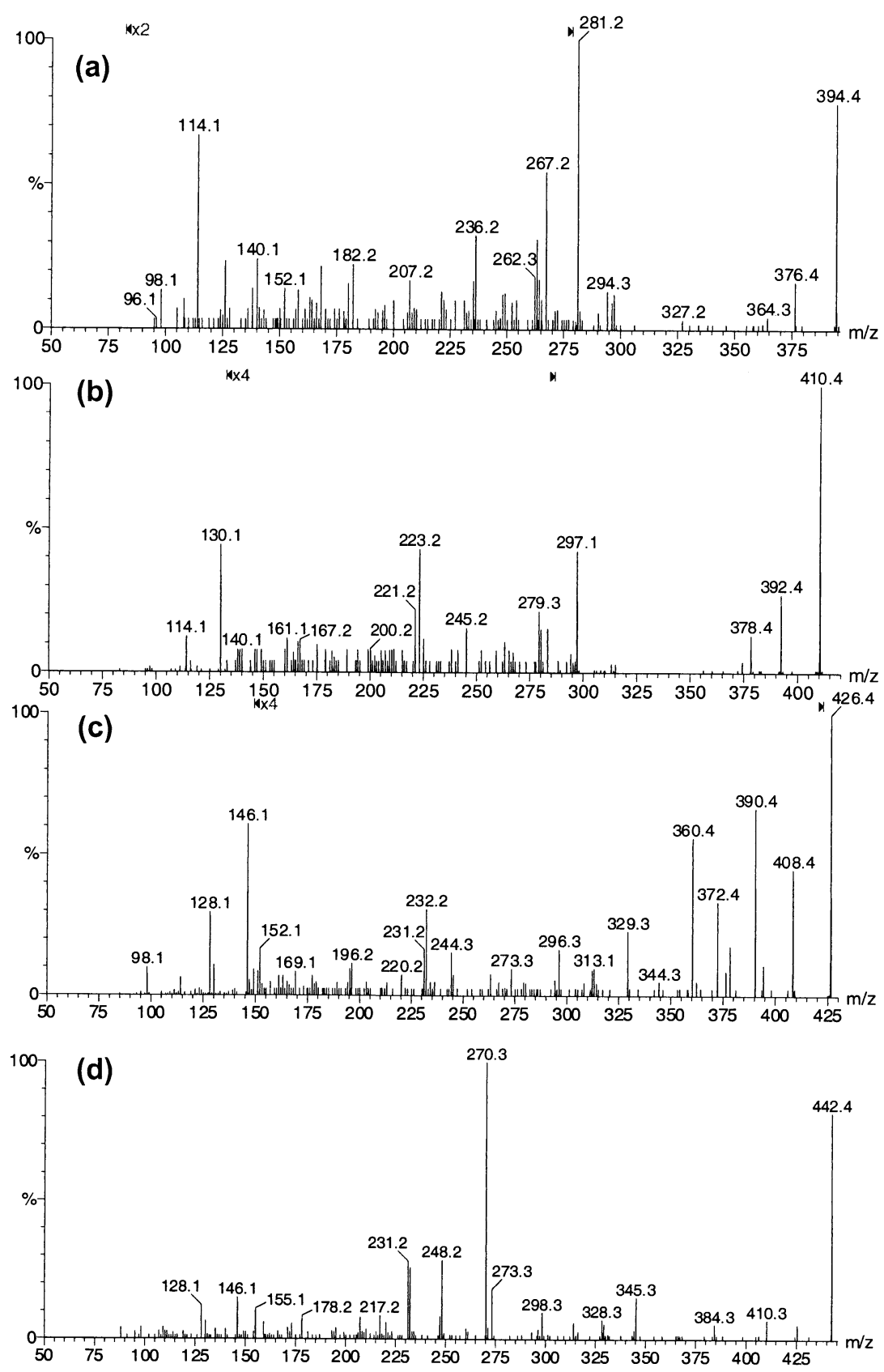

Figure 3. ES-MS/MS spectra of the carbon and oxygen-centered radical adducts of linoleic acid at (a) $\mathrm{m} / \mathrm{z} 394$ and (b) $\mathrm{m} / \mathrm{z} 410$, (c) $\mathrm{m} / \mathrm{z} 426$, and (d) $\mathrm{m} / \mathrm{z} 442$.

linoleic acid molecule generating a hydroperoxide. However, this specie is not stable in solution and decomposes in the presence of metal ions to an alkoxyl radical, which in turn may either be stabilized by hydrogen abstraction forming a hydroxy group or by capture of a DMPO molecule to form the alkoxyl DMPO adducts at $m / z 408-410$. The formation pathway and the structures of the carbon- and oxygen-centered adducts are shown in Scheme 2.

The reaction of linoleic acid with DMPO in the presence and absence of hydrogen peroxide (under conditions similar to those reported above) was also monitored by ES-MS (Figure 2a and b). The ES-MS spectrum of linoleic acid in the presence $\mathrm{H}_{2} \mathrm{O}_{2}$ and DMPO shows high abundance ions at $m / z 392,394,408$,

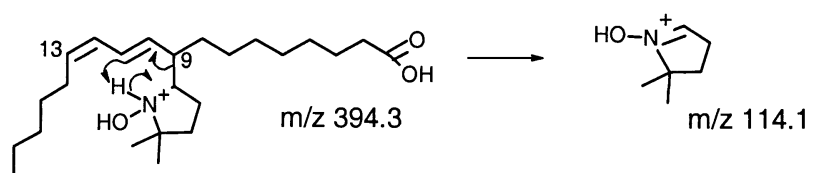

Scheme 3. Proposed mechanism for the formation of the protonated molecule of DMPO, at $\mathrm{m} / \mathrm{z} 114$ from the ion at $\mathrm{m} / \mathrm{z} 394$. 
Table 1. Fragment ions observed in the MS/MS spectra of open structures of DMPO spin adducts of linoleic acid radicals (\% of relative abundance normalised to base peak

\begin{tabular}{|c|c|c|c|c|}
\hline Fragments & $m / z 394$ & $m / z 410$ & $m / z 426$ & $m / z 442$ \\
\hline$[\mathrm{DMPO}+\mathrm{H}]^{+}$ & $114(35)$ & $114(30)$ & $114(10)$ & $114(<5)$ \\
\hline$[\mathrm{DMPO}-\mathrm{O}+\mathrm{H}]^{+}$ & - & $130(100)$ & $130(20)$ & $130(<5)$ \\
\hline$[\mathrm{DMPO}-\mathrm{OO}+\mathrm{H}]^{+}$ & - & - & $146(100)$ & $146(15)$ \\
\hline$-\mathrm{H}_{2} \mathrm{O}$ & $376(20)$ & $392(60)$ & $408(20)$ & $424(10)$ \\
\hline$-2 \mathrm{H}_{2} \mathrm{O}$ & - & $374(10)$ & $390(30)$ & \\
\hline$-97 \mathrm{Da}\left(\mathrm{C}_{11}-\mathrm{C}_{12}\right.$ cleavage isomer $\left.\mathrm{C}_{9}\right)$ & $297(15)$ & $313(10)$ & $329(25)$ & $345(20)$ \\
\hline-113 (loss of DMPO) & $281(100)$ & $297(80)$ & $313(15)$ & $329(10)$ \\
\hline$-113-\mathrm{H}_{2} \mathrm{O}$ & $263(30)$ & $279(10)$ & & $311(<5)$ \\
\hline
\end{tabular}

410,424 , and 426. This is in agreement with the results obtained by FAB-MS. The ES-MS spectrum showed additional ions at $\mathrm{m} / \mathrm{z} 440$ and 442,16 Da above $\mathrm{m} / \mathrm{z} 424$ and 426 ions mentioned above, which could be attributed to alkyl peroxyl radical adducts containing a hydroxy group. The hydroxy group could be located at either at $\mathrm{C}_{8}$ or $\mathrm{C}_{14}$. These ions can also be attributed to an alkyl epoxyperoxyl spin adduct. Besides the formation of an additional hydroxy group, the epoxy formation from alkoxyl radicals has already been reported in lipid peroxidation, during a study of linoleic carboncentered radicals using the spin trap POBN [11, 21].

Ions at $m / z 130,146,158,211,227$, and 354 (data not shown) were identified as DMPO radicals resulting from the oxidative conditions in solution, and were previously detected by FAB-MS [16] and ES-MS [17].

In order to elucidate the structure of the ions identified as DMPO radical adducts of the linoleic acid oxidation reaction, collision induced decomposition of the ES produced ions was performed. ES-MS/MS spectra of the ions were analyzed, rather than the FAB-MS/ MS, because of the higher sensitivity and resolution achieved with the QTOF 2 instrument. As referred to previously, several isomers of DMPO adducts can be formed although the most probable location of the spin bond is on $\mathrm{C}_{9}$ or $\mathrm{C}_{13}$. In the MS-MS experiments, since there was no previous separation, all the isomers were selected, so different fragmentation pathways derived from different isomers are overlapped. Some evidence of this will be shown in the discussion.

\section{MS/MS Spectra of Open Structures of DMPO Radical Adducts}

The ES-MS/MS mass spectra obtained for the ions at $\mathrm{m} / \mathrm{z} 394,410,426$, and 442, corresponding to open structures of carbon and oxygen-centered DMPO ad- ducts of the linoleic acid radical formed by oxidation, are shown in Figure 3a, b, c, d. In the MS/MS spectra of all adducts, an abundant fragment ion at $m / z 114$ is observed, corresponding to the protonated molecule of $\mathrm{DMPO},[\mathrm{DMPO}+\mathrm{H}]^{+}$, thus confirming that all these ions are DMPO adducts. A proposed mechanism for the formation of the ion at $m / z 114$ is presented in Scheme 3. In the MS/MS spectrum of the alkoxyl adduct, $m / z 410$, it is possible to observe the ion at $m / z 130$, corresponding to the protonated molecule of the DMPO hydroxy adduct (DMPO - OH) [16, 17], thus confirming that this adduct is an alkoxyl radical adduct. In the MS/MS spectra of the adducts at $m / z 426$ and 442 , a fragment at $\mathrm{m} / \mathrm{z} 146$ corresponding to the protonated molecule of the DMPO peroxyl adduct (DMPO - OOH) was observed, thus confirming the presence of the linoleic peroxyl radical adducts. Common fragment ions observed in the MS/MS spectra are summarized in Table 1.

Other common fragmentations observed in all spectra were the loss of water (Table 1), and combined loss of two water molecules. Loss of one water molecule can occur either from the carboxylic acid group (due to the acidity of the $\alpha$ hydrogen adjacent to the carbonyl group) forming an unsaturated terminal carbonyl group (Scheme 4), and/or from the DMPO moiety.

The major fragment ion of the carbon-centered adduct at $m / z 394$ corresponds to the loss of $113 \mathrm{Da}$. This fragmentation is probably due to loss of the DMPO moiety. This fragmentation pathway is observed in all of the spectra, although with variable relative abundances. Another common fragmentation pathway corresponds to the combined loss of water and loss of 113 $\mathrm{Da}$, which suggests the loss of water from the carboxylic moiety with the charge being retained on the carbonylic group formed, resulting in the acylium ion, $\mathrm{RC}=\mathrm{O}^{+}$. Loss of $113 \mathrm{Da}$ can also be due to the combined loss of

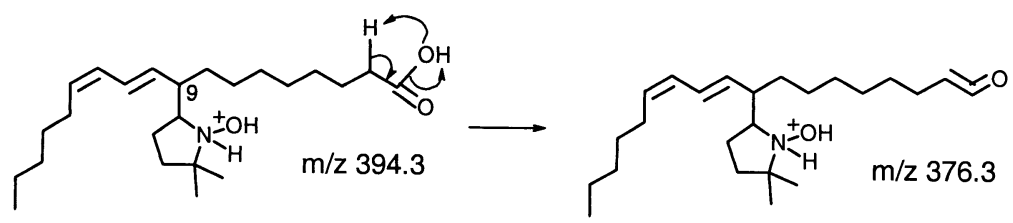

Scheme 4. Loss of water from the carboxylic acid group, showed for the ion at $\mathrm{m} / \mathrm{z} 394$. 

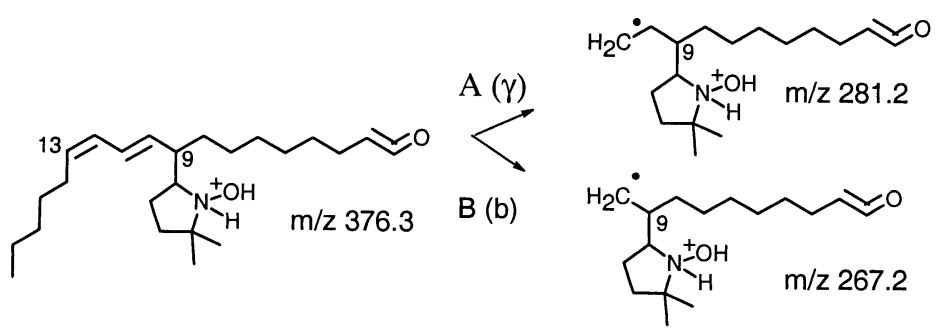

Scheme 5. Fragment ions formed from the combined loss of water and homolytic cleavage of (a) the bond between $C_{11}-C_{12}$ and (b) the bond between $C_{10}-C_{11}$ of the isomer $C_{9}$ at $m / z 394$.

one water molecule and the homolytic scission between $\mathrm{C}_{11}-\mathrm{C}_{12}$ of the spin adduct containing the DMPO linked to the $\mathrm{C}_{9}$ with the charge being retained at the DMPO. This mechanism presupposes double bond migration, as represented in Scheme 5a, for the adduct at $\mathrm{m} / \mathrm{z} 394$. The same fragmentation could occur for the other radical adducts. In all of the MS/MS spectra, fragment ions from the combined loss of water and homolytic cleavage between $\mathrm{C}_{10}-\mathrm{C}_{11}$ of the isomer $\mathrm{C}_{9}$ (Scheme $5 \mathbf{b}$ ) were observed.

The cleavage of $\mathrm{C}-\mathrm{C}$ bond by homolytic scission, between $C_{11}-C_{12}$, can also occur without loss of water, generating the fragment ion at $\mathrm{m} / \mathrm{z} 297$ for the spin adduct at $m / z$ 394, as represented in Scheme 6 . The spin adduct at $\mathrm{m} / \mathrm{z} 410,426$, and 442 generates the fragment ions at $\mathrm{m} / \mathrm{z} 313,329$, and 345 respectively. These fragmentation pathways provide evidence for the presence of the spin trap at $\mathrm{C}_{9}$.

A common fragmentation pathway corresponding to 1,4-elimination involving the cleavage of the $C_{7}-C_{8}$ bond, occurring either for isomer $C_{9}$ or isomer $C_{13}$, leads to the fragment ion at $\mathrm{m} / \mathrm{z} 264$ (adduct at $\mathrm{m} / \mathrm{z}$ 394), 280 (adduct at $m / z$ 410), and 296 (adduct at $m / z$ 426). The mechanism for this fragmentation is represented in Scheme 7 for the adduct at $\mathrm{m} / \mathrm{z} 394$.

Scission of the $\mathrm{C}_{10}-\mathrm{C}_{11}$ bond with the DMPO molecule located at $\mathrm{C}_{13}$ occurs in almost all adducts. For some adducts it occurs combined with loss of water from the DMPO moiety. This is evidence for the presence of DMPO linked to the $\mathrm{C}_{13}$. This fragmentation combined with loss of water occurs for the adducts at $\mathrm{m} / \mathrm{z} 394$ and 410, forming the ions at $\mathrm{m} / \mathrm{z} 207$ and 223 respectively. This fragmentation pathway, without loss of water, occurs for ion at $\mathrm{m} / \mathrm{z} 442$ forming the ion at $\mathrm{m} / \mathrm{z}$ 273.

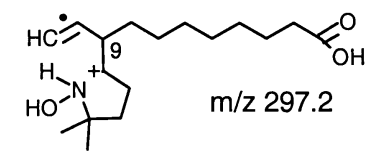

Scheme 6. Proposed structure for the fragment ion formed by to $\mathrm{C}-\mathrm{C}$ bond homolytic scission, between $\mathrm{C}_{11}-\mathrm{C}_{12}$, of isomer $\mathrm{C}_{9}(\mathrm{~m} / \mathrm{z}$ 394).
MS/MS Spectra of the Carbon-Centered Adduct at $\mathrm{m} / \mathrm{z} 394$

The MS/MS spectra of the carbon-centered adduct at $\mathrm{m} / \mathrm{z} 394$ (Figure 3a) shows, low-mass ions that seem to be due to charge remote fragmentation. Charge-remote fragmentation occurs probably after loss of water and DMPO molecule, originating alkyl acylium ions. Charge-remote fragmentation has already been observed in MS/MS spectra of anilide derivatives of fatty acids, obtained with a Q-TOF2 instrument [22]. In the adducts from the other clusters $(\mathrm{m} / \mathrm{z} 410,426$, and 442), charge-remote fragmentation also seems to occur with formation of alkyl acylium ions, but is less extensive, presumably because of the presence of an oxygen atom on the alkyl chain after loss of DMPO. A group of low-mass ions at $m / z 126,140,152,168,180$, and 182, attributable to alkyl acylium radical ions, is represented in Scheme 8. They are probably formed by combined loss of one water molecule and loss of DMPO moiety, the charge being retained in the acylium ion, with cleavage in the vicinity of the double bonds ions. Interestingly, homolytic cleavages occurred predominantly between the $\mathrm{C}_{12}-\mathrm{C}_{13}$ and $\mathrm{C}_{9}-\mathrm{C}_{8}$ bond, thus giving an indication of the location of the double bonds, namely at $C_{13}$ and $C_{9}$. The fragment ions at $m / z 364$ can be due to 1,4-hydrogen rearrangement mechanism, with loss of $\mathrm{C}_{2} \mathrm{H}_{2}$ and $\mathrm{H}_{2}$.

\section{MS/MS Spectra of the Alkoxy Adduct at m/z 410}

The MS/MS spectrum obtained for the ion at $m / z 410$, attributed to the alkoxyl DMPO adduct of linoleic acid (shown in Figure 3b), showed a fragment ion at $m / z 263$ formed because of the combined loss of DMPO - O (loss of $129 \mathrm{Da}$ ) and water from the precursor ion. The lower-mass fragment ions observed at $\mathrm{m} / \mathrm{z} 140$ $\left(\mathrm{C}_{8} \mathrm{H}_{16} \mathrm{CO}^{+}\right), 167 \quad\left(\mathrm{C}_{10} \mathrm{H}_{19} \mathrm{CO}^{+}\right)$and $194(\mathrm{OH}-$ $\left.\mathrm{C}_{11} \mathrm{H}_{17} \mathrm{CO}^{+\cdot}\right)$, correspond to alkyl acylium radical ions.

\section{MS/MS Spectra of the Peroxyl Adduct at m/z 426}

The MS/MS spectrum obtained for the ion at $m / z 426$ (Figure 3c), previously ascribed to the alkyl peroxyl spin adduct (Scheme 1f), showed abundant fragment ions at $m / z 408,390$, and 372 that can be attributed to the 


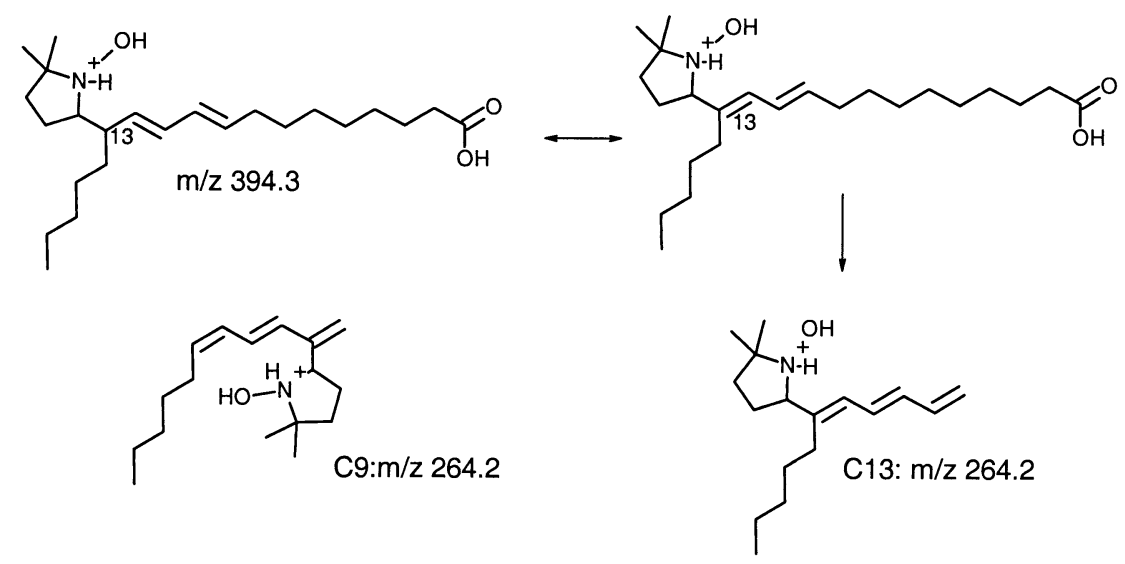

Scheme 7. 1,4-elimination involving the cleavage of the linkage of $C_{7}-C_{8}$ occurring either in isomer $\mathrm{C}_{9}$ or isomer $\mathrm{C}_{13}$.

loss of one, two and three water molecules. The combined loss of three water molecules could indicate the presence of an alkoxy radical adduct, with a hydroxy group in the alkyl chain. The presence of a fragment ion at $m / z 130$ seems to justify the presence of this isomer of the peroxyl radical adduct. The fragment ions at $m / z 146$ and 263, attributed to combined loss of water and $(\mathrm{DMPO}+\mathrm{OO})$, confirms that it is a alkyl peroxyl spin adduct. The ion at $\mathrm{m} / \mathrm{z} 128$ can occur by the loss of water from the peroxyl-DMPO adduct $(\mathrm{m} / \mathrm{z} 146)$.

The fragment ion at $m / z 296$ formed by 1,4-hydrogen rearrangement with cleavage of the $\mathrm{C}_{7}-\mathrm{C}_{8}$ bond adjacent to the hydroxy group, suggests the contribution of an alkoxyl spin adduct placed at $\mathrm{C}_{13}$ containing a hydroxy group at $C_{8}$. The fragment ion at $m / z 378$ could be formed by 1,4-hydrogen rearrangement, corresponding to the loss of $\mathrm{C}_{3} \mathrm{H}_{6}$ plus $\mathrm{H}_{2}$, and the fragment ion at $\mathrm{m} / \mathrm{z} 360$ due to further loss of water.

Low mass fragment ions at $m / z 152\left(\mathrm{C}_{9} \mathrm{H}_{16} \mathrm{CO}^{+}\right), 169$ $\left(\mathrm{OH}-\mathrm{C}_{9} \mathrm{H}_{16} \mathrm{CO}^{+}\right)$, and $196\left(\mathrm{OH}-\mathrm{C}_{11} \mathrm{H}_{19} \mathrm{CO}^{+}\right)$, were attributed to alkyl acylium radical ions formed by homolytic cleavage of the $\mathrm{C}-\mathrm{C}$ bond in the vicinity of the spin trap, after combined loss of the DMPO moiety and a water molecule.

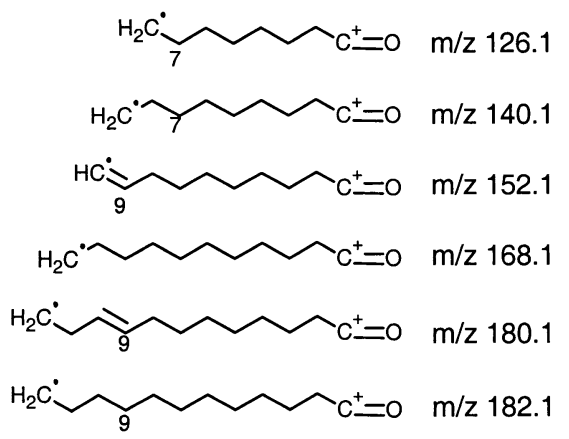

Scheme 8. Proposed structures for the alkyl acylium radical ions observed in the MS/MS spectrum of the ion at $\mathrm{m} / \mathrm{z} 394$.
MS/MS Spectra of the DMPO Adduct at $\mathrm{m} / \mathrm{z} 442$

The ion at $m / z 442$ (Figure 3d), showing a difference of 16 Da relative to the ion at $\mathrm{m} / \mathrm{z} 426$, can be attributed either to a monohydroxy alkylperoxyl spin adduct and/or to an epoxyalkyl peroxyl spin adduct. The presence of ions at $\mathrm{m} / \mathrm{z} 146$ and 128 confirms that it is a peroxyl adduct of DMPO.

The MS/MS spectrum of this adduct (Figure 3d) shows an abundant fragment ion at $\mathrm{m} / \mathrm{z} 270$. This fragment ion, not observed in the MS/MS spectra at $\mathrm{m} / \mathrm{z}$ 426 ion, can be due to heterolytic cleavage of the $\mathrm{C}_{9}-\mathrm{C}_{10}$, by rearrangement of the epoxide, from isomer $C_{13}$ (Scheme 9).

The fragment ion at $\mathrm{m} / \mathrm{z} 384$ is originated from hydrogen rearrangement involving the hydroxy group, with cleavage of the $\mathrm{C}_{14}-\mathrm{C}_{15}$ bond (Scheme 10). This fragment ion indicates that the ion at $m / z 442$ is also a monohydroxy alkyl peroxyl radical adduct.

\section{MS/MS Spectra of Cyclic Structure Radical Adducts}

The ES-MS spectrum (Figure 2) contained ions at $\mathrm{m} / \mathrm{z}$ 392, 408, 424, and 440 which are 2 Da lower than the previously described open structures. These ions were attributed to cyclic structures of carbon-centered and oxygen-centered spin adducts (Scheme 1c, e, g). The MS/MS spectra of these ions are shown in Figure 4a, b, $c$, d. As can be seen from the MS/MS spectra, these ions show different fragmentation pathways than the open structures, although some fragment ions are common to both.

Under the oxidative conditions present in solution, the DMPO molecule can be oxidized to 5,5-dimethyl-1pyrroline-3-ene-N-oxide $(\mathrm{m} / \mathrm{z} 112)$, which can, in turn, form an adduct with the linoleic acid alkyl radical, resulting in the formation of these ions with a 2 mass units decrease when compared with the initial ions at $\mathrm{m} / \mathrm{z} 392,408,424$, and 440 . The presence of an abundant 


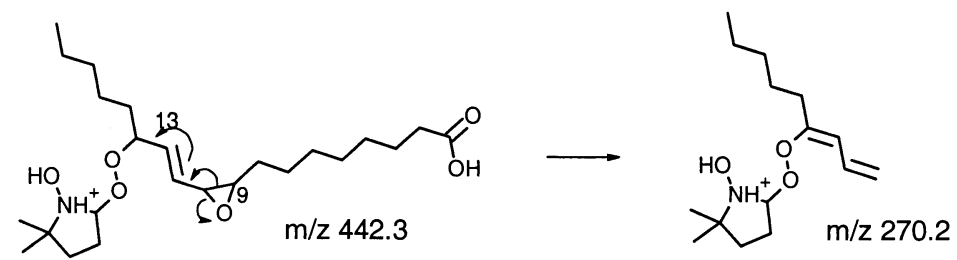

Scheme 9. Fragmentation pathway of the DMPO adduct at $\mathrm{m} / \mathrm{z} 442$.

fragment ion at $m / z 114$ in the MS/MS spectra (Figure 4) along with the absence of a fragment ion at $\mathrm{m} / \mathrm{z} 112$, suggests that these ions correspond to the cyclic adduct of the carbon and oxygen-centered spin adducts and not to the open structure containing the oxidised DMPO molecule linked to the linoleic acid radicals. Moreover, the fragment ion at $m / z 114$ in all the MS/MS spectra confirms the presence of the DMPO spin adducts. The mechanism proposed for the formation of the ion at $\mathrm{m} / \mathrm{z}$ 114 from the cyclic adduct at $\mathrm{m} / \mathrm{z} 392$ is shown in Scheme $\mathbf{1 1 .}$

Fragment ions at $\mathrm{m} / \mathrm{z} 130$ and 146 observed in the MS/MS spectra of ions at $\mathrm{m} / \mathrm{z} 408$ and 424 respectively (Figure $4 \mathrm{~b}$ and c), confirm the presence of the hydroxyl and peroxyl radical adducts, as was observed for the open structures (Table 1). Other common fragmentations are observed such as the loss of one and two molecules of water, the loss of DMPO molecule combined with loss of water, and cleavage of $C_{11}-C_{12}$ bond of isomer $\mathrm{C}_{9}$ (Table 2).

A common fragment ion at $m / z 360$, observed in the Figure 4 a, b, c, formed due to loss of 32,48 , and $64 \mathrm{Da}$, respectively, are attributable to loss of two, three, and four oxygen atoms, respectively. For the hydroxyl and peroxyl spin adducts, respectively, losses of $\mathrm{O}$ and $\mathrm{O}_{2}$ were observed. The loss of $\mathrm{O}_{2}$ in the case of the carbon-centered adduct at $\mathrm{m} / \mathrm{z} 392$ can only be explained if the DMPO is linked to the carboxylic group as is shown in Scheme 12. An intramolecular ring has already been suggested to occur in the bis DMPO adducts [16].

\section{MS/MS Spectra of the Cyclic Carbon-Centered Adduct at $\mathrm{m} / \mathrm{z} 392$}

The MS/MS spectrum of this adduct (Figure 4a) shows a series of ions that can be attributed to charge remote

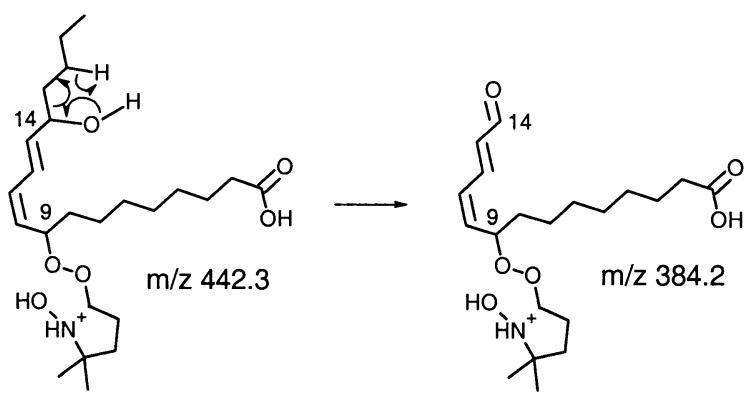

Scheme 10. Mechanism proposed for the cleavage of the $C_{14}-C_{15}$ bond of isomer $\mathrm{C}_{9}(\mathrm{~m} / \mathrm{z} 442)$. fragmentation of the ion formed after loss of DMPO and also after the combined loss of DMPO and water. These two series of charge remote formed ions overlap in the mass spectrum. In the other closed-ring adducts $(\mathrm{m} / \mathrm{z}$ 408, 424, and 440) charge remote fragmentation also seems to occur with formation of alkyl acylium ions, but less extensively. The series of low mass fragment ions at $m / z \quad 126 \quad\left(\mathrm{C}_{7} \mathrm{H}_{14} \mathrm{CO}^{+}\right), \quad 138 \quad\left(\mathrm{C}_{8} \mathrm{H}_{14} \mathrm{CO}^{+}\right), \quad 140$ $\left(\mathrm{C}_{8} \mathrm{H}_{16} \mathrm{CO}^{+\cdot}\right), 154\left(\mathrm{C}_{9} \mathrm{H}_{18} \mathrm{CO}^{+\cdot}\right), 166\left(\mathrm{C}_{10} \mathrm{H}_{18} \mathrm{CO}^{+\cdot}\right), 180$ $\left(\mathrm{C}_{11} \mathrm{H}_{20} \mathrm{CO}^{+\cdot}\right), 182\left(\mathrm{C}_{11} \mathrm{H}_{22} \mathrm{CO}^{+}\right), 194\left(\mathrm{C}_{12} \mathrm{H}_{22} \mathrm{CO}^{+*}\right), 208$ $\left(\mathrm{C}_{13} \mathrm{H}_{24} \mathrm{CO}^{+}\right), 210\left(\mathrm{C}_{13} \mathrm{H}_{26} \mathrm{CO}^{+}\right)$are attributed to homolytic cleavages of the unsaturated chain, forming alkyl acylium radical cations. Fragment ion at $m / z 249$ can result from homolytic cleavage between $\mathrm{C}_{8}-\mathrm{C}_{9}$ involving the spin trap located at the $C_{9}$.

\section{MS/MS Spectra of the Alkoxyl Adduct at m/z 408}

The presence, in the MS/MS spectrum of the ion at $\mathrm{m} / \mathrm{z}$ 408 (Figure $4 \mathrm{~b}$ ) and of a fragment ion at $\mathrm{m} / \mathrm{z} 130$, identified as $[(\mathrm{DMPO}+\mathrm{O})+\mathrm{H}]^{+}$, is evidence for the presence of a hydroxyl spin adduct. Ions at $\mathrm{m} / \mathrm{z} 263$ and 249 correspond to the cleavage of the $C_{7}-C_{8}$ and the $\mathrm{C}_{8}-\mathrm{C}_{9}$ bonds, respectively, with the DMPO bond located at $\mathrm{C}$. These fragmentations suggest the presence of a carbon-centered radical adduct of hydroxy linoleic acid. Other fragment ions observed in the low mass region at $\mathrm{m} / z \mathrm{z} 149\left(\mathrm{C}_{9} \mathrm{H}_{13} \mathrm{CO}^{+}\right), 151\left(\mathrm{C}_{9} \mathrm{H}_{15} \mathrm{CO}^{+}\right), 165$ $\left(\mathrm{C}_{10} \mathrm{H}_{17} \mathrm{CO}^{+}\right), 182\left(\mathrm{C}_{11} \mathrm{H}_{22} \mathrm{CO}^{+}\right), 194\left(\mathrm{C}_{12} \mathrm{H}_{22} \mathrm{CO}^{+\cdot}\right), 196$ $\left(\mathrm{OH}-\mathrm{C}_{11} \mathrm{H}_{19} \mathrm{CO}^{+\cdot}\right)$, and $212\left(\mathrm{OH}_{2}-\mathrm{C}_{11} \mathrm{H}_{18} \mathrm{CO}^{+}\right)$or $(\mathrm{OH}-$ $\mathrm{C}_{12} \mathrm{H}_{23} \mathrm{CO}^{+}$), can be assigned to alkyl radical ions attributable to homolytic cleavage of the bonds near the location of the DMPO bond.

\section{MS/MS Spectra of the Cyclic Alkyl Peroxyl} Adduct at $\mathrm{m} / \mathrm{z} 424$

The MS/MS spectrum of the ion at $m / z 424$ (Figure 4c) exhibited an abundant fragment ion at $\mathrm{m} / \mathrm{z} 146$ corresponding to $[(\mathrm{DMPO}+\mathrm{OO})+\mathrm{H}]^{+}$, thus confirming that is an alkyl peroxyl spin adduct. The fragment ion at $\mathrm{m} / \mathrm{z} 279$ may be attributed to the loss of an oxidized DMPO molecule (DMPO - OO), and the ion at $\mathrm{m} / \mathrm{z} 261$ is due to combined loss of DMPO - OO and water.

The fragment ion at $\mathrm{m} / \mathrm{z} 294$, resulting from the 1,4-hydrogen rearrangement in isomer $C_{13}$, involving the hydroxy group placed at the $\mathrm{C}_{8}$ and cleavage of $\mathrm{C}_{8}-\mathrm{C}_{7}$ bond, suggests the contribution of a alkoxyl adduct with an hydroxy group in the chain as an isomer of the alkyl peroxyl adduct. This mono-hydroxy alkoxyl 

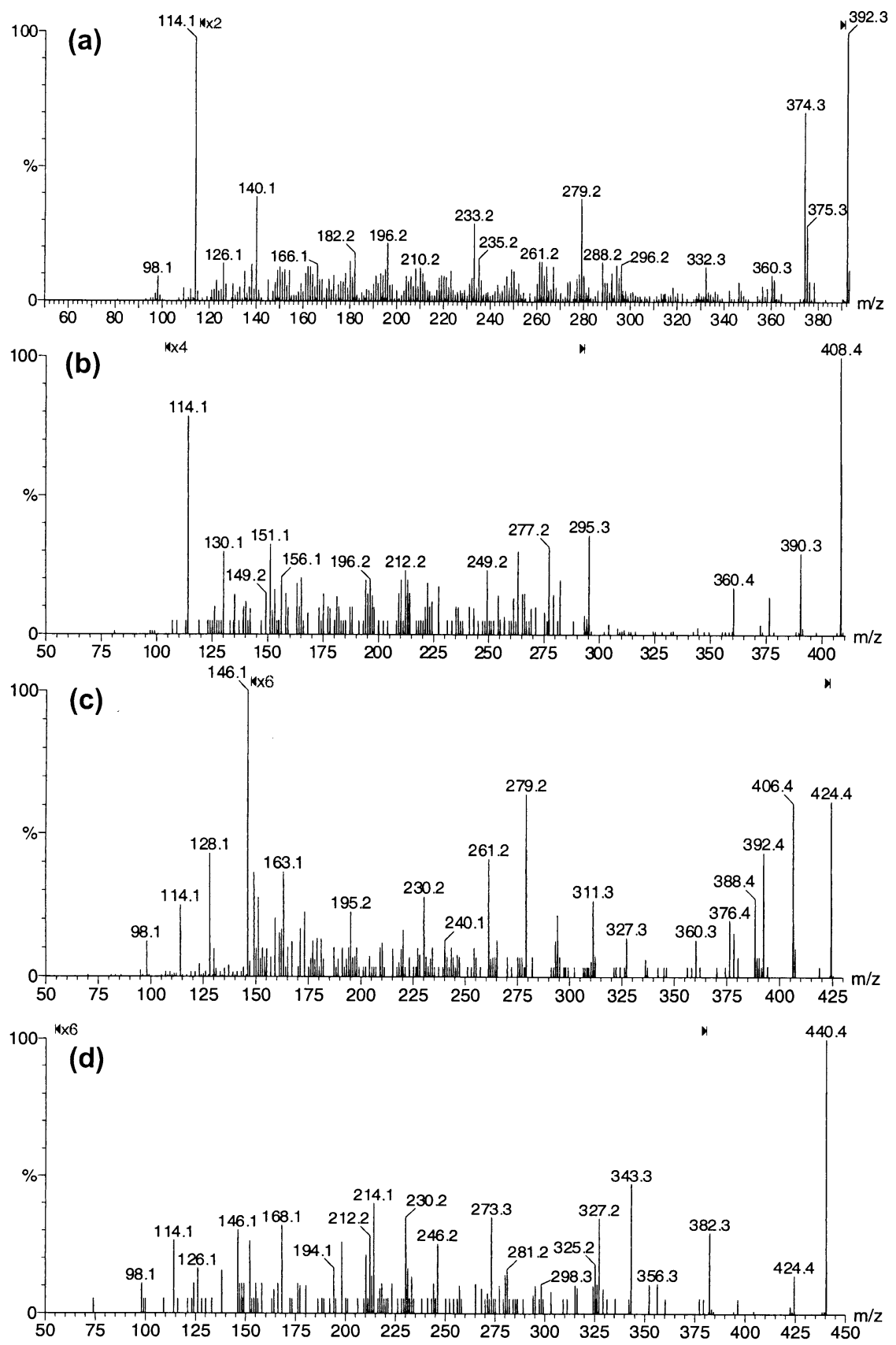

Figure 4. ES-MS/MS spectra of the carbon and oxygen-centered radical adducts of linoleic acid of (a) $\mathrm{m} / \mathrm{z}$ 392, (b) $\mathrm{m} / \mathrm{z} 408$, (c) $\mathrm{m} / \mathrm{z} 424$, and (d) $\mathrm{m} / \mathrm{z} 440$.

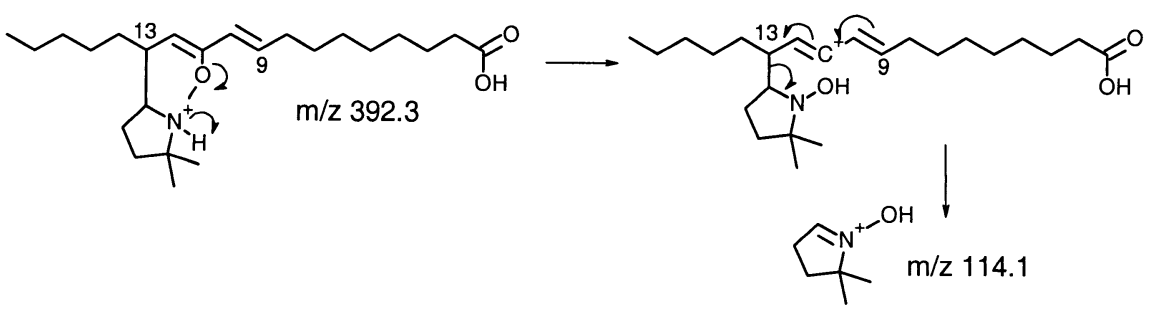

Scheme 11. Proposed mechanism for the formation of the ion at $m / z 114$ from the cyclic adduct at $\mathrm{m} / \mathrm{z} 392$. 
Table 2. Fragment ions observed in the MS/MS spectra of cyclic structures of DMPO spin adducts of linoleic acid (\% of relative abundance normalized to base peak)

\begin{tabular}{|c|c|c|c|c|}
\hline Fragments & $m / z 394$ & $m / z 410$ & $m / z 426$ & $m / z 442$ \\
\hline$[\mathrm{DMPO}+\mathrm{H}]^{+}$ & $114(100)$ & $114(55)$ & $114(25)$ & $114(20)$ \\
\hline$[\mathrm{DMPO}-\mathrm{O}+\mathrm{H}]^{+}$ & & $130(20)$ & $130(10)$ & \\
\hline$[\mathrm{DMPO}-\mathrm{OO}+\mathrm{H}]^{+}$ & & & $146(100)$ & $146(20)$ \\
\hline$-\mathrm{H}_{2} \mathrm{O}$ & 374 (35) & $390(80)$ & $406(10)$ & $442(<5)$ \\
\hline$-2 \mathrm{H}_{2} \mathrm{O}$ & & $372(10)$ & $388(5)$ & \\
\hline$-97\left(C_{11}-C_{12}\right.$ cleavage isomer $\left.C_{9}\right)$ & $295(10)$ & $311(5)$ & $327(5)$ & $343(30)$ \\
\hline-113 & $279(20)$ & $295(100)$ & $311(5)$ & $327(20)$ \\
\hline$-113-\mathrm{H}_{2} \mathrm{O}$ & $261(10)$ & $277(10)$ & $293(<5)$ & \\
\hline
\end{tabular}

adduct was also suspected to occur in the open adduct. The mechanism for its origin is similar with the one presented in Scheme 10, involving the hydroxy group similar to the adduct at $m / z$ 442. The fragment ion at $m / z$ 230 may result from cleavage of the $\mathrm{C}_{13}-\mathrm{C}_{12}$ bond adjacent to the spin trap in isomer $\mathrm{C}_{13}$ with loss of $\mathrm{C}_{11} \mathrm{H}_{22} \mathrm{CO}_{2} \mathrm{H}$. The fragment ions at $m / z 149\left(\mathrm{C}_{9} \mathrm{H}_{13} \mathrm{CO}^{+}\right)$, $151 \quad\left(\mathrm{C}_{9} \mathrm{H}_{15} \mathrm{CO}^{+}\right), \quad 163 \quad\left(\mathrm{C}_{10} \mathrm{H}_{15} \mathrm{CO}^{+}\right), 181 \quad(\mathrm{OH}-$ $\left.\mathrm{C}_{10} \mathrm{H}_{16} \mathrm{CO}^{+}\right), 195\left(\mathrm{OH}-\mathrm{C}_{11} \mathrm{H}_{18} \mathrm{CO}^{+}\right)$, and $209(\mathrm{OH}-$ $\mathrm{C}_{12} \mathrm{H}_{20} \mathrm{CO}^{+}$), correspond to alkyl acylium radical fragment ions.

\section{MS/MS Spectra of the DMPO Adduct at $m / z 440$}

The MS/MS spectrum of the ion at $m / z 440$ (Figure $4 d$ ), unlike all the other MS/MS spectra, showed fragment ions with very low relative abundance. It was possible to observe the presence of fragment ions at $m / z 114$ and 146, confirming the presence of an alkyl peroxyl spin adduct containing an hydroxy group. Fragment ion at $\mathrm{m} / \mathrm{z} 327$ is due to loss of DMPO moiety. The presence of a fragment ion at $m / z 424$ results from the loss of $O$. The formation of the fragment ion at $m / z 382$ is originated by a mechanism similar to that presented for the formation of the fragment ion at $m / z 384$ from the adduct at $m / z$ 442 (Scheme 10). The fragments observed in the low mass region were attributed to unsaturated alkyl acylium radical ions $\left(126\left(\mathrm{C}_{7} \mathrm{H}_{14} \mathrm{CO}^{+\cdot}\right), 138\left(\mathrm{C}_{8} \mathrm{H}_{14} \mathrm{CO}^{+\cdot}\right)\right.$, $152\left(\mathrm{C}_{9} \mathrm{H}_{16} \mathrm{CO}^{+\cdot}\right), \quad 168\left(\mathrm{OH}-\mathrm{C}_{9} \mathrm{H}_{15} \mathrm{CO}^{+\cdot}\right), \quad 194(\mathrm{OH}-$ $\left.\mathrm{C}_{11} \mathrm{H}_{17} \mathrm{CO}^{+\cdot}\right)$, $198\left(\mathrm{OH}-\mathrm{C}_{11} \mathrm{H}_{21} \mathrm{CO}^{+\cdot}\right), \quad 212 \quad\left(\mathrm{OH}_{2}-\right.$ $\mathrm{C}_{11} \mathrm{H}_{18} \mathrm{CO}^{+}$) or $\left(\mathrm{OH}-\mathrm{C}_{12} \mathrm{H}_{23} \mathrm{CO}^{+}\right)$.

\section{Conclusions}

FAB-MS, ES-MS, and MS/MS have proven to be useful for the identification and characterisation of DMPO spin adducts of linoleic acid, namely alkyl, alkoxyl and alkyl peroxyl spin adducts. Both FAB-MS and ES-MS spectra gave similar results, allowing the identification of linoleic acid peroxidation products, but due to the higher sensitivity of ES-MS, it was possible to observe characteristic new adducts in the ES-MS spectrum. Both carbon-centered and oxygencentered adducts of DMPO were found to occur, namely alkoxyl, peroxyl, hydroxyalkoxyl, and hydroxyperoxyl radical adducts. Epoxy adducts were also identified.

Characteristic fragment ions, such as the fragment ion at $\mathrm{m} / \mathrm{z} 114$ and the loss of $113 \mathrm{Da}$ were observed in the MS/MS spectra of all adducts, thus confirming that they are DMPO adducts. In the alkoxyl radical adducts, a fragment ion at $m / z 130$ confirmed the presence of the alkoxyl radical, and the fragment ion at $\mathrm{m} / z 146$ and loss of 145 Da confirmed the presence of the alkyl peroxyl adduct. Alkoxyl radical adducts with hydroxyl group in the alkyl chain, an isomer of the peroxyl adduct, were also found. Alkyl peroxyl DMPO adducts containing an hydroxyl group were also observed in the MS spectra, and the corresponding MS/MS spectra showed the characteristic fragment ions at $m / z 114$ and 146, and loss of 113 and 145 Da. Although the experimental approach used in this work does not allow identifying unambiguously the different isomers that are present, fragmentation observed in the vicinity of the DMPO linkage suggested the occurrence of structural isomers containing the DMPO moiety both at $\mathrm{C}_{9}$ and $\mathrm{C}_{13}$.

Adducts with the DMPO linked to the carboxylic acid group forming an intramolecular ring were also found. Additional fragmentation involved loss of one and two molecules of oxygen, or loss of one molecule of oxygen and an oxygen atom, for the alkyl, alkoxyl, and peroxyl adducts, respectively.

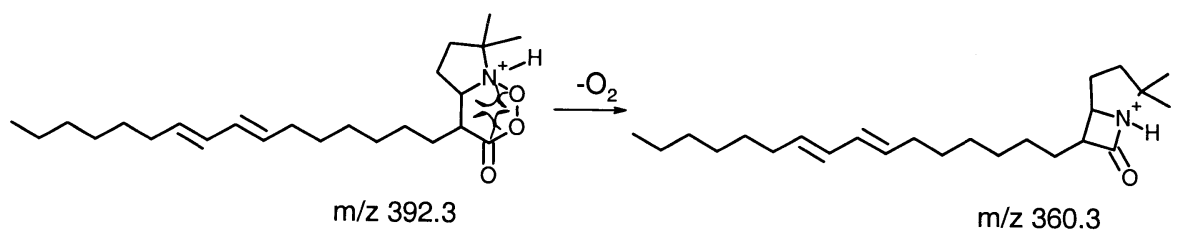

Scheme 12. Loss of $\mathrm{O}_{2}$ from the adduct at $\mathrm{m} / \mathrm{z} 392$ forming the fragment ion at $\mathrm{m} / \mathrm{z} 360$. 


\section{Acknowledgments}

The authors gratefully acknowledge to Foundation for Science and Technology (FCT) for the financial support provided by the project POCTI 33279/99 and PhD. Grant to Ana Reis (SFRH/BD/ 10358/2002). The authors also acknowledge the Research Unit 62/94 Química Orgânica, Produtos Naturais e Agro-alimentares.

\section{References}

1. Jackson, M. J. Free Radical in the Pathogeneses of Tissue Damage in Calcium, Oxygen Radical and Cellular Damage; (Society for Experimental Biology Seminar Series, 46); Duncan, C. J., Ed., Cambridge University Press: Cambridge, 1991; pp 11-16.

2. Pincemail, J. Free Radicals and Antioxidants in Human Diseases. In Analysis of Free Radicals in Biological Systems; Favier, A. E.; Cadet, J.; Kalyanaraman, B.; Fontecave, M.; Pierre, J. L.; Birkhäuser Verlag: Berlin, 1995; pp. 83-98.

3. Shigenaga, M. K.; Hagen, T. M.; Ames, B. N. Oxidative Damage and Mithocondrial Decay in Aging. Proc. Natl. Acad. Sci. 1994, 91, 10771-10778.

4. Wills, E. Evaluation of Lipid Peroxidation in Lipids and Biological Membranes. Biochemical Toxicology: A Practical Approach; In: Snell, K.; Mullock, B., Eds.; IRL Press: Oxford, 1987; 127-152.

5. (a) Liochev, S. I. The Mechanism of Fenton-Like Reactions and Their Importance for Biological Systems. A Biologist's View. In Metal Ions in Biological Systems, Sigel, A.; Sigel, H., Eds., Vol. XXXVI; Marcel Dekker, Inc: New York, NY, 1999; pp 1-40. (b) Sergent, O.; Morel, I.; Cillard, J. Involvent of Metal Ions in Lipid Peroxidation. Biological Implications in Metal Ions in Biological Systems, Sigel, A.; Sigel, H., Eds., Vol XXXVI; Marcel Dekker, Inc: New York, NY, 1999; pp 251-262.

6. Knecht, K. T.; Mason, R. P. In vivo Spin Trapping of Xenobiotics Free Radical Metabolites. Arch. Biochem. Biophys. 1993, 303, 185-194.

7. Rota, C.; Barr, D. P.; Martin, M. V.; Guengerich, F. P.; Tomasi, A.; Mason, R. P. Detection of Free Radicals Produced from the Reaction of Cytochrome. P-450 with Linoleic Acid Hydroperoxide. Biochem. J. 1997, 328, 565-571.

8. Qian, S. Y.; Wang, H. P.; Schafer, F. Q.; Buettner, G. R. EPR Detection of Lipid-Derived Free Radicals from PUFA, LDL, and Cell Oxidations. Free Rad. Cell Med. 2000, 29, 568-579.

9. Iwahashi, H.; Albro, P. W.; McGrown, S. R.; Tomer, K. B.; Mason, R. P. Isolation and Identification of $\alpha$-(4-Pyridyl-1Cxide)-N-Tert-Butylnitrone Radical Adducts Formed by the Decomposition of Hydroperoxides of the Linoleic Acid by Soybean Lipoxygenase. Arch. Biochem. Biophys. 1991, 285, 172180.

10. Iwahashi, H. High-Performance Liquid Chromatographic Determination of Linoleic Acid Peroxide-Derived Radicals Using Electrochemical Detection. J. Chromatogr. A. 2000, 904, 197-202.
11. Qian, S. Y.; Tomer, K. B.; Yue, G. Guo, Q;; Kadiisha, M. B. Mason, R. P. Characterization of the Initial Carbon-Centered Pentadienyl Radical and Subsequent Radicals in Lipid Peroxidation: Identification via On-Line High Performance Liquid Chromatography/Electron Spin Resonance and Mass Spectrometry. Free Rad. Biol. Med. 2002, 33, 998-1009.

12. Iwahashi, H.; Parker, C. E.; Mason, R. P.; Tomer, K. B. Combined Liquid Chromatography/Electron Paramagnetic Resonance Spectrometry/Electrospray Ionization Mass Spectrometry for Radical Identification. Anal Chem. 1992, 64, 22442252.

13. Iwahashi, H.; Nishizaki, K.; Takagi, I. Cytochrome $c$ catalyzes the Formation of Pentyl Radical and Octanoic Acid Radical from Linoleic Acid Hydroperoxide. Biochem. J. 2002, 361, 57-66.

14. Dikalov, S. I.; Mason, R. P. Spin Trapping of Polyunsaturated Fatty Acid-Derived Alkyl Peroxyl Radicals: Reassignment to Alkoxyl Radical Adducts. Free Rad. Biol. Med. 2001, 30, 187197.

15. Parker, C. E.; Iwahashi, H.; Tomer, K. B. Spin-Trapped Radicals: Determination by LC-TSP-MS. J. Am. Soc. Mass Spectrom. 1991, 2, 413-418.

16. Domingues, P.; Domingues, M. R. M.; Amado, F. M. L.; Ferrer-Correia, A. J. Detection and Characterization of Hydroxyl Radical Adducts by Mass Spectrometry. J. Am. Soc. Mass Spectrom. 2001, 12, 1219-1241.

17. Jurva, U.; Wikström, H. V.; Bruins, A. P. Electrochemically Assisted Fenton Reaction: Reaction of Hydroxyl Radicals with Xenobiotics Followed by On-Line Analysis with High-Performance Liquid Chromatography/Tandem Mass Spectrometry. Rapid Commun. Mass Spectrom. 2002, 16, 1934-1940.

18. Domingues, M. R. M.; Domingues, P.; Reis, A.; Fonseca, C.; Amado, F. M. L.; Ferrer-Correia, A. J. V. Identification of Oxidation Products and Free Radicals of Tryptophan by Mass Spectrometry. J. Am. Soc. Mass Spectrom. 2003, 14, 406-416.

19. Folch, J.; Lees, M.; Stanley, G. H. S. A Simple Method for the Isolation and Purification of Total Lipids from Animal Tissues. J. Biol. Chem. 1957, 226, 497-509.

20. Spiteller, P.; Kern, W.; Reiner, J.; Spiteller, G. Aldehydic Lipid Peroxidation Products Derived from Linoleic Acid. Biochim. Biophys. Acta. 2001, 1531, 188-208.

21. Marnett, L. J.; Wilcox, A. L. Polyunsaturated Fatty Acid Alkoxyl Radicals Exist as Carbon-Centered Epoxyallylic Radicals: A Key Step in Hydroperoxide-Amplified Lipid Peroxidation. Chem. Res. Toxicol. 1993, 6, 413-416.

22. Crow, F. W.; Cragun, J. D.; Johnson, K. L.; Ruiz, M. V. de la; Paz, M. P.; Naylor, S. On-Line HPLC-UV-Mass Spectrometry and Tandem Mass Spectrometry for the Rapid Delineation and Characterization of Differences in Complex Mixtures: A Case Study Using Toxic Oil Variants. Biomed. Chromatogr. 2002, 16, 311-318. 